\title{
An outcome of expert-oriented digitalization of university processes
}

\author{
Altti Lagstedt ${ }^{1,2}$ (D) Juha P. Lindstedt ${ }^{2} \cdot$ Raine Kauppinen $^{2}$ \\ Received: 30 March 2020 / Accepted: 17 June 2020 / Published online: 22 June 2020 \\ (C) The Author(s) 2020
}

\begin{abstract}
Digitalization challenges the way in which business processes are seen. The potential for enhancement is even recognized in business areas that traditionally have little to do with IT. Even though universities have long-standing traditions of how work is organized, they have not been eager to adopt digitalized processes. Because core university processes rely on highly skilled experts, digitalizing processes are not as straightforward as they would be in more mechanical work. We developed an expertoriented digitalization model (EXOD) for the digitalization of university processes and tested it using a case study. After digitalizing a core process, we interviewed the experts involved. The results show the usefulness and adaptability of the model. Based on the results, we recommend further studies to refine and test the model more comprehensively. In addition, based on the adaptability of the model, we recommend it as a baseline for university process digitalization projects in general.
\end{abstract}

Keywords Thesis management - Thesis process · Education digitalization · University processes $\cdot$ Expert $\cdot$ Model

\section{Introduction}

Due to digitalization, the importance of information systems (IS) has grown in business areas that are not normally considered to be IT-oriented (Fitzgerald et al. 2014; Borg et al. 2018). Universities are no exception, even though some university processes have a long and rather changeless tradition that was inherited from as far back as the fifteenth century. Although long traditions may be an obstacle to the digitalization of university processes, there are other obstacles as well. Universities' core education processes rely

Altti Lagstedt

altti.lagstedt@haaga-helia.fi

1 Turku School of Economics, Turku University, Rehtorinpellonkatu 3, 20500 Turku, Finland

2 Haaga-Helia University of Applied Sciences, Ratapihantie 13, 00520 Helsinki, Finland 
heavily on expert work, and the amount of mechanical work is rather minimal. Experts with strong opinions and expertise combined with high autonomy have to be taken into account in university digitalization projects.

In this study, we selected one of the core processes of every university: the thesis process. Although it is critical for universities, the thesis process is not typically considered a systematic one; it is viewed more as the repetition of a unique handicraft that is done using the supervisors' best skills and will.

The challenges of the thesis process have been recognized, and some related work has been done in the areas of both quality improvement and ICT system support (Aghaee 2015; Lagstedt 2015; Karunaratne 2018). One of the tested thesis process support systems is SciPro (Hansson 2014), which has been studied from the perspective of the student-supervisor interaction and the effective implementation of the process (Hansen and Hansson 2015; Karunaratne 2018). Scaling the process for a more extensive implementation has also been studied from a quality (Larsson and Hansson 2011) and resource management point of view (Hansson 2014).

However, in addition to quality and resource aspects, the issues related to scaling the process include integrations with other (core) processes and both manual and ICT-based systems. Existing research (Hansson 2014) identifies the thesis process as a core activity in universities, but the process and the systems integration at the organizational level have not been discussed in detail; they have a considerable impact on, for example, the level of automation, information availability, and quality at the organizational level. In addition, the prior literature seems to consider the thesis process only as a research process (see e.g. Karunaratne 2018), which is not the reality at all universities. Other types of theses are also used (see e.g., Lagstedt 2015), and in different disciplines, various aspects are emphasized within the same type of thesis. Furthermore, by applying Davenport's (2010) knowledge work classification, thesis supervising can be categorized as an expert model of knowledge work, whereby experts organize their work individually and are not ready to consent to a mechanical, "cookbook" approach (Davenport 2010). The thesis process and the supporting IS must be flexible enough to enable efficient supervision of different types of theses.

Because the prior literature considers the university process-system integration on a limited organizational and individual level, and because concentrating primarily on teaching and learning and minimally on the efficiency of work (see e.g., Coskun 2015; Pihir et al. 2018) to improve the situation, we developed an expert-oriented digitalization model (EXOD) to digitalize universities' processes (Kauppinen et al. 2019).

To test the developed model, we formulated the following research questions:

RQ1: What are the experiences of the expert-oriented digitalization model?

RQ2: How was the user involvement realized in the digitalization project?

RQ3: How did the users experience the digitalized process when it was implemented as an IS (Konto thesis monitoring and guidance system)?

To answer these research questions, we studied a thesis process digitalization project that was conducted at the Haaga-Helia University of Applied Sciences (HH) in Finland between 2016 and 2019. 


\section{Theoretical background}

Although the terms digitalization and digital transformation are rather new (see e.g. Pihir et al. 2018), the phenomenon itself is less so. In recent decades, there has been extensive discussion about information systems' supporting processes and business-IT alignment. Some basic problems and challenges of digitalization have already been detected, and different kinds of solutions have been proposed and tested. Often, however, only parts of the phenomenon are taken into consideration, different researchers have different preferred approaches, and the holistic picture is missing. In practice, these different points of view are not separate from each other, but vice versa: they are heavily overlapping and intertwined so that everything affects everything. We consider the earlier studies and different points of view as valuable, and when creating an overall picture of digitalization and digital transformation, we see it is important to take the different points of view from the earlier studies into account.

\subsection{Business process development}

Digitalizing business processes is not risk-free. If digitalization is done solely by automating processes into IS as they are, the existing problems may be fixed, but the potential of IS is not exploited to the fullest extent. However, according to Matt et al. (2015), it is common for IT infrastructure development to be emphasized in digital transformations at the expense of business development. In addition, Argyris (1977) points out that people seldom do exactly what they claim to do, and automating the assumed process brings out this discrepancy: the new IS may follow the known process model exactly, but it is not suitable for use (Lagstedt and Dahlberg 2018a). At the management level, digital transformation strategies should go beyond processes (Matt et al. 2015), but making real changes may require a company to question its assumptions about itself, and this could be a real challenge (Fitzgerald et al. 2014). Thus, if not considered thoroughly, automating the existing processes could be a tempting option, but without careful consideration from a strategic point of view, it could be seen as a symptom of functional stupidity (Alvesson and Spicer 2012). However, digitalization can be consciously carried out at different levels. Westerman et al. (2014) (in Pihir et al. 2018) grouped digital changes into three categories: 1) substitution (i.e., automatization), 2) extension (the improvement of old processes via IT), and 3) transformation (the redefinition of processes via IT). As Venkatraman (1994) points out, automating the existing processes could, in some cases, be an organization's conscious and rational choice to avoid making radical changes to its processes. An organization may choose to automatize only its existing practices instead of attempting major and costly reengineering projects.

According to Venkatraman (1994), IT-enabled business transformation can be loosely classified into two categories: evolutionary and revolutionary levels. The former requires minimal changes to business processes, while the latter requires fundamental changes to existing processes. We see that Westerman et al.'s (2014) levels 1 and 2 belong to the evolutionary level, while level 3 belongs to the revolutionary level. Venkatraman claimed that the revolutionary approach would enable organizations to benefit more, but the costs (efforts) of the change would be higher. Consequently, there is no right, wrong, or optimal level of business transformation. The 
cost and potential benefits, as well as the enablers and inhibitors of the organization, should be taken into account, and each case should be discussed separately (Venkatraman 1994). Although additional (techno)change management practices have been proposed (see e.g., Markus 2004), this approach is still used to classify the level of transformational practices (see e.g., Wang et al. 2018), especially in the case of predigital organizations' process development (Chanias et al. 2019).

Davenport and Short (1990) present a five-step model for process redesign. The first step is to develop a business vision and process objectives. This is a rather general level and should be done as part of strategic planning (Matt et al. 2015). The second step of the Davenport and Short (1990) model is to select (a) suitable process(es) to be redesigned. They point out that it is not necessary to undergo all the processes of the organization exhaustively for development but that it is sufficient to identify the most significant or problematic process. The selection of the right process is also emphasized by Fitzgerald et al. (2014). The third step of the Davenport and Short (1990) model is to understand and measure the selected process(es) to identify current problems and set a baseline for improvements. Here, it is also important to take possible legacy systems into account (Fitzgerald et al. 2014). The fourth step is to identify IT levers - that is, how IS can enhance the current process or enable completely new kinds of approaches. In this step, it is also important to remember that when new technologies are used, there will be changes in value creation and that structural changes are also needed (Matt et al. 2015). The final step is to design and build a prototype of the process by implementing the new process on a pilot basis and modifying it as necessary (Davenport and Short 1990).

In process development, it is not sufficient to consider the organizational level: individual levels must also be taken into account, especially in regard to knowledge work (Davenport 2010). When Taylor composed his principles of scientific management, the assumptions about humans were rather mechanistic; they were depicted as replaceable components doing simple, repetitive tasks, and by optimizing these tasks, maximum efficiency could be achieved (Taylor 1913). However, this is an oversimplification, and later process-development models, such as business process management (BPM), emphasize the role of people and culture (vom Brocke and Sinnl 2011). People are more complex than parts of a machine; they are not fully rational (Simon 1997; Alvesson and Spicer 2012), nor are they always reliable. Moreover, as previously mentioned, Argyris (1977) maintains that there is a difference between what people say they do and what they actually do. This kind of coverup culture, or inhibiting loops of organizational learning as Argyris (1977) calls them, hides the real causes of the problems (Argyris 1977), and if individuals are not taken into account in the development phase, the real causes of the problems will not be solved.

As Davenport (2010) points out, knowledge work is difficult to structure and is seldom seen as a process. In addition, knowledge workers easily resist instructions and models that are given by management, and they view a formal process approach as a bureaucratic, procedural annoyance (Davenport 2010). Although knowledge workers resist change, there are examples in which knowledge work is significantly improved through process management (Davenport 2010).

Davenport (2010) formulated a model of four approaches to clarify different knowledge work situations (see Fig. 1). 


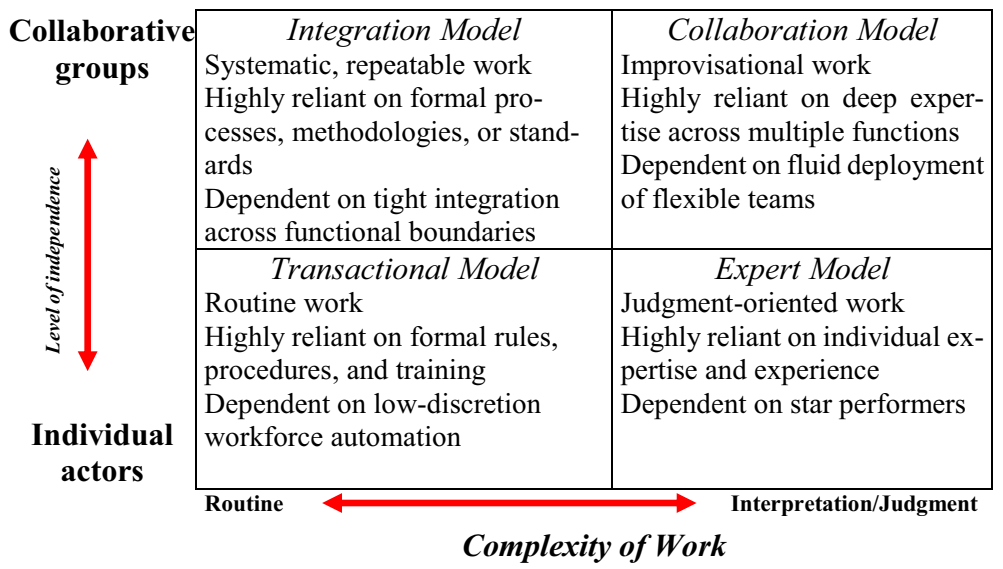

Fig. 1 Four approaches to knowledge work (Davenport 2010)

Like many other university processes, thesis supervising is clearly more about judgment and interpretation carried out individually; consequently, we place it in the "expert model" category. According to Davenport (2010), expert work can be improved via processes, but workers themselves easily resist change and strict, cookbooktype process models. Therefore, expert model processes should instead consist of higher-level guidelines that give expert workers sufficient flexibility to decide how to perform the actual work (Davenport 2010). To overcome the expert workers' resistance and structure their work, Davenport (2010) recommends finding a way to embed a computer (i.e., IS) in the middle of the work process. However, IS should not be an obstacle to experts reaching their full potential (Wenger and Snyder 2000).

\subsection{Information systems development}

When business processes are digitalized, it is important to understand the possibilities and restrictions of different IS development methods (ISDMs). Another important viewpoint is how ISDMs can be combined to enable business process development.

From a control point of view, ISDMs can be loosely classified into two methodological categories: plan-driven and change-driven methods (Moe et al. 2012). Plan-driven IS development methods were dominant at the end of the twentieth century, whereas the popularity of change-driven ISDMs has grown over the last two decades and appears to be mainstream today (Theocharis et al. 2015). In plandriven IS development, planning and development are divided into separate phases. The assumption is that every aspect of development work - that is, objectives and their required metrics, tasks, money, and resources - can be planned thoroughly and in advance. Development begins immediately after the planning phase is completed.

Plan-driven methods, such as the waterfall method, are a straightforward way to develop software, but there are many known problems; for example, early mistakes are found late and are difficult and costly to resolve. The assumption is that no changes will occur during software development- that is, what is defined at the beginning will be implemented in the later phases. Even if all the definitions are formulated correctly, it 
does not guarantee success in IS development because circumstances might have changed along the way (Hansen and Lyytinen 2010).

In change-driven development such as agile methods, the idea is that the whole IS is not planned at once; rather, planning and development are undertaken in small steps. After each step, the situation is re-evaluated, and the necessary changes are made to the objectives. Each development step results in a new release of the IS. The change-driven approach is not problem-free, either. Because of its nature, it is highly likely to have radical, unplanned changes in the code during the development, which cause incoherencies in the software architecture; because these incoherencies are normally not resolved during the agile development step (sprint), they become technical debt (Cunningham 1992), thereby causing more development and maintenance challenges in the long run. Moreover, if the client has no clear vision and priorities change constantly, or if there is no shared understanding of what is to be delivered, the scope of the development becomes unclear, and quality assurance becomes challenging (Moe et al. 2012; Dahlberg and Lagstedt 2018). Despite the rather high success rate of projects undertaken using agile methods, $61 \%$ are still not considered to be successful (Hastie and Wojewoda 2015); therefore, agile ISDMs do not guarantee the success of ISD projects (Dahlberg and Lagstedt 2018).

One alternative is to use a hybrid approach, whereby parts of plan-driven and change-driven development are combined (Theocharis et al. 2015). Because no method fits all cases, it is important to discuss and select the method on a case-by-case basis (Lagstedt and Dahlberg 2018b).

\subsection{Change management}

Although business process change is organizational, the role of individuals in process change is remarkable, especially in knowledge work. One component of the change is change management. It is natural for humans to resist change, and if the change is not managed well, the new process and the IS supporting it may not be used, regardless of how efficient they are. Some change management models are rather mechanical, whereby organizations are more or less seen as machines (Cameron and Green 2009), and we do not see them as applicable to the expert work digitalization. Here, we have come from two not-so-mechanistic angles for change management: first, we consider the social aspects of change management, and after that, we go through the technical acceptance point of view. Since business process development relies heavily on social aspects in its digitalization and digitalization in technological solutions, we see both approaches combined together as valuable here.

In contrast to rather mechanical change management models, organizations are also seen as evolving organisms where different social aspects should be considered. A rather famous and largely used example of this approach is Kotter's eight-step model (Kotter 1995), in which the change becomes established only when "new behaviours are rooted in social norms and shared values" (Kotter 1995). In Kotter's eight-step model, the idea is that the change process goes through change steps, and skipping the steps creates problems. The model includes the following steps: 1) establishing a sense of urgency, 2) forming a powerful guiding coalition, 3) creating a vision, 4) communicating the vision, 5) empowering others to act on the vision, 6) planning for and creating short-term wins, 7) consolidating improvements and producing more change, 
and 8) institutionalizing new approaches (Kotter 1995). Emphasizing empowerment and responsibilities aligns with Matt et al. (2015), who warn about digital transformation that is carried out in a half-hearted manner, as well as with Markus (2004), who focuses on (techno)change management practices (e.g., new job designs, new skills training, restructuring changing $\mathrm{HR}$ policies, and new incentives) to ensure that organizational change is accomplished.

From the technological solutions point of view, it is important to remember that business process change often manifests as a new IS. The success of the new IS also represents the success of the business process change. On the other hand, if the process change is a failure, no IS can rectify the situation. However, if the new IS is not well suited to the process and the needs of the individuals, it is possible that the individuals will accept the process change itself but will refuse to use the IS that supports the new process. Consequently, Kotter's model can be a usable tool to communicate and guide the business process change, but it does not automatically legitimate the new IS. It is, therefore, natural to consider how new ISs are used at the individual level and how this affects business process digitalization.

There are several models showing how technological changes are accepted and accounted for in organizations. These models can be loosely divided into two groups: theories examining the adaptation of new technology at the organizational level and those examining individual-level adaptation (Haneem et al. 2019). In the first group, there are theories such as the innovation diffusion theory (IDT) and the technologyorganization-environment theory (TOE), which are suitable tools for discussing how certain technological innovation is adopted in different types of organizations (Venkatesh et al. 2003; Haneem et al. 2019). However, in this study, we are more interested in tailor-made solutions digitalizing one university process at a time, having individuals strongly committed to the change; these general-level organizational models were not seen as suitable here.

In the second group, where an individual point of view is emphasized, there are theories such as the unified theory of acceptance and use of technology (UTAUT), the technology acceptance model (TAM) and its predecessor, and the theory of reasoned action (TRA) (Davis et al. 1989; Haneem et al. 2019). For the developed model, we took these three (TRA, UTAUT and TAM) and examined them more closely.

In the TRA, the user's behavioral intention (BI) to use the new technology (IS) is a combination of the person's attitude (the user's expectation of the consequences of using the new system) and a subjective norm (Davis et al. 1989). Because the subjective norm is difficult to estimate, we considered this model to be difficult to apply as a tool for guiding business process digitalization.

According to the UTAUT, the user's intent to use the new technology (IS) depends on 1) performance expectancy, 2) effort expectancy, 3) social influence, and 4) facilitating conditions (Venkatesh et al. 2003). In this case, we saw the social influence as the problematic component of the model: on the one hand, it moves the model toward an organizational level, and on the other hand, social influence is difficult to evaluate beforehand because all the different features of IS are not necessarily known in advance. To keep technology adoption as part of the digitalization model, user-centric, and clear to use, we decided to apply the TAM, which is also a simpler model than the UTAUT.

The TAM, which is an extension of the TRA, proposes that perceived usefulness and perceived ease of use affect the BI to use a system (Davis et al. 1989). Therefore, 
to get users to use a new system, they have to clearly see that the system increases work performance and can be used without additional effort. As stated, the TAM is simple; in general, it does not explain the variance of user intentions to use information technology as well as other models do, for example, the UTAUT (Venkatesh et al. 2003). However, according to Venkatesh et al. (2003), in Mathieson's (1991) study, the TAM explained $70 \%$ of the variance, which is the same percentage that Venkatesh et al. (2003) presented for the UTAUT. Therefore, even though the explanation percentage of the TAM is found to be lower in other studies, we considered it good enough to be useful and simple enough to be utilized.

One aspect is timing and the order of changes. As previously mentioned, not all problems in process change are easily seen (Alvesson and Spicer 2012) or recognized (Argyris 1977). Thus, it is not always possible to deal with them early, and Kotter's eight-step model is difficult to apply as such. Cooper and Zmud (1990) proposed an IT implementation process in which the diffusion of IT does not occur all at once but rather as a gradual process. This approach is well suited to the digitalization case, wherein development occurs in small, iterative steps, as is the case in expert-oriented university process development.

We claim that Cooper and Zmud's model is useful when actual process change (and the supporting IS) is implemented step by step, whereas Kotter's model is effective when the change is communicated to users and when social aspects are accounted for, bearing the objectives of the TAM (usefulness and ease of use) in mind. In addition, when development and changes are undertaken step by step over a long period, there is a risk of innovation fatigue (Fitzgerald et al. 2014), i.e., tiredness of continuous change; because of this, it is especially important to communicate the objectives and steps of each specific digitalization case.

\subsection{Expert-oriented digitalization model}

Based on the theories of the business process, IS development, and change management, we formulated an expert-oriented digitalization model (EXOD) for knowledge work, especially for university processes. The EXOD has four main steps:

1. Initiation. Undertake process identification and explore development opportunities. Find the potential benefits of the digitalization of the selected process and communicate these to the users (experts) involved. Form an effective development group with experts in IS, process development, and the process in question. With regard to the development group, define the desired level of automation of the digitalized process (Cooper and Zmud 1990; Davenport and Short 1990; Kotter 1995; Davenport 2010).

2. Process re-engineering emphasis. Define the major, high-level changes to be made to the developed process, as well as the main requirements for the developed IS. Select a suitable IS development method for the case. Develop a new process with users (experts), and implement it as widely as possible without a new IS. Communicate the potential usefulness of the IS, and empower the experts to act on this vision (Davis et al. 1989; Davenport and Short 1990; Venkatraman 1994; Kotter 1995; Davenport 2010; Lagstedt and Dahlberg 2018b). 
3. IS development emphasis. Develop a process-supporting, requirement-based IS in cooperation with the experts. Perform iterative development with pilot projects and make changes to the process where needed. Develop only those features which are essential to the organization and support expert work. The developed IS should not enforce the process too rigidly; instead, experts' work flexibility and autonomy should be considered and communicated to all parties (Davenport and Short 1990; Kotter 1995; Davenport 2010; Theocharis et al. 2015)

4. Stabilization. Induce the experts to commit the digitalized process as a normal activity. Make minor refinements to the IS as needed (Cooper and Zmud 1990; Kotter 1995; Davenport 2010; Theocharis et al. 2015). When a process is stabilized, the achieved benefits, as well as the harm to experts and to the organization, can be evaluated.

\section{Methodology}

\subsection{Research method}

In the case-study research, we followed the recommendations of Yin (2009). We relied extensively on the four data-collection sources that Yin (2009) recommends: documentation, archival records, participant observation, and interviews. In the analysis, the main emphasis was on the interviews; the other sources were considered complementary.

Because one of the researchers was responsible for the thesis process development and another for the development of the IS (Konto) supporting it, we had access to the thesis process development, as well as to all Konto's development documentation (process models, notes, product backlogs, version history, plans, emails, and guidelines). We also utilized Konto's logs and registers as supporting data in order to understand the actual usage of the IS. In addition, as supervisors and thesis coordinators, we used and guided the digitalized process and made participant observations during it.

The interviews were conducted by applying an interview method protocol developed by Dahlberg et al. (2016). Questions were presented to the interviewee either face to face or via video call. The interviewer recorded and presented the responses immediately before moving to the next question. The act of recording the responses gave the interviewees the ability to validate the typed answers immediately and allowed us to easily continue conducting interviews until data saturation was reached because we were able to assess saturation immediately following each interview.

In total, 27 experts were interviewed. The interviewees were chosen based on their above-average activity around Konto at different stages. As the interviewees had extensive experience in the work and roles they were representing, the interviews can be described as expert interviews (Bogner et al. 2009). The experts who were interviewed included the Director of Corporate Planning and IT Services, the Head of Library Services, the Head of Student Services, the Manager of Education Services, degree program directors (2), thesis coordinators (5), thesis supervisors (8), student office secretaries (2), and students (6).

The interview had two parts: the first part covered the process of digitalization (RQ1 and RQ2), and the second part focused on the resulting process and Konto (RQ3). Of 
the total number of interviewees, 13 responded to the first part and 25 to the second, while 11 were able to answer both parts.

\subsection{Case: Thesis process}

The thesis process as a core activity (Hansson 2014) is often considered relatively simple: the supervisor as the expert advises, and the student writes the thesis (Karunaratne 2018). However, in practice, the process is more complicated (Aghaee 2015; Hansen and Hansson 2015). For example, in our case study, the process at the Haaga-Helia University of Applied Sciences $(\mathrm{HH})$ included other experts, such as the thesis coordinator (organizes information sessions, checks students' thesis ideas, and assigns supervisors) and personnel from degree program management (oversee supervisors' and coordinators' workload) and administration (publish the resulting thesis and record the grade). The thesis process was selected for digitalization in discussions with the $\mathrm{HH}$ chief information officer (CIO), the director of administration, program managers, student office, education services, and thesis coordinators. The thesis process was selected to achieve benefits for the administration, supervisors, and students.

The process was digitalized using the EXOD model. In the initiation step (before 2014), HH described its core processes, revealing that the thesis process was one of the most complicated. There were systems in use, e.g., the course-oriented e-learning platform Moodle (similar to Blackboard), which could be seen as legacy systems, but they were not considered very useful when project-oriented personalized learning is in question. There are some thesis management systems, such as SciPro (see Hansson 2014), but they were not seen as suitable for the HH thesis management.

In addition, the student registry system changed at that point, and the new system provided open interfaces, which enabled a new kind of feature for digitalizing the thesis process. The benefits of digitalization were apparent; therefore, work started with experts on the process and on IS development with a process re-engineering emphasis step during the 2014-2017 period, resulting in a revised process for the basis of the IS development. The main requirements for IS were integration with data sources, automatic data transfer, and being a modern platform that supported mobile use.

A hybrid approach (Theocharis et al. 2015) to IS development with high-level planning and iterative and incremental development loops was selected to support expert involvement. During the IS development emphasis step (2016-2019), the Konto tool was developed based on the requirements. Changes to the process were implemented and communicated.

As a result, a new digitalized thesis management process was implemented, see Fig. 2. The major benefits of digitalization are automatic real-time monitoring of the progress (deadlines and alerts, Integrated automatic monitoring bar in Fig. 2); documented tasks for students; activity remarks and comments; acceptance of phases; integrated assessment; full log of the projects; all the messages and files in the same place and connected to the project. There is no limitations to the number of supervisors and students; there are different levels of reporting and different levels of transparency (according to the user groups: 1 students, 2 thesis supervisors, 3 coordinators \& program directors). The developed system, Konto, also has accessible by a variety of media, such as smart phones, pads, and computers. 


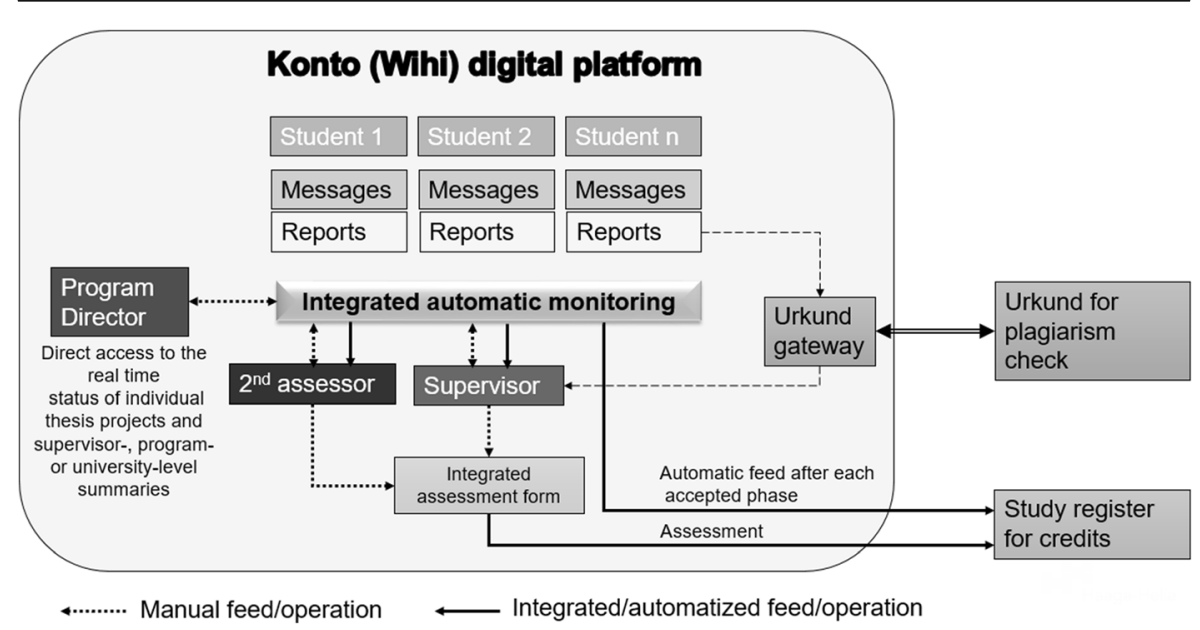

Fig. 2 Digitalized thesis process: Konto (Wihi) digital platform

After the fall 2018 test period, the Konto tool was launched for full use with thesis projects starting from January 2019, and this resulted in a stabilization step (from 2019) in which the digitalized process was undertaken as a normal activity. However, refinements are still done when needed.

\section{Results}

\subsection{Research questions 1 and 2}

The first part of the interview consisted of identifying the role of the interviewees and responding to six open-ended questions. It also included an opportunity to provide open-ended comments. The answers were coded based on the theory presented in Chapter 2 (business process development, IS development, and change management) and in themes in the research questions (expectations, experiences, and the realization of involvement). One code (service promise) emerged based on the answers.

In this part, 10 of the 13 interviewees performed a single role, two performed two roles, and one performed three roles. The fields of expertise covered administration (4), degree program management (2), thesis coordination (5), and thesis supervision (6).

RQ1: What are the experiences of the expert-oriented digitalization model?

Regarding the experiences, the majority of the interviewees (10 of the 13) had formed expectations early, immediately after being involved in the digitalization. From the administrative, management, and coordination viewpoints expressed in the interviews (translated to English), process visibility (at every level of the organization), process automation (automating parts of the process), and statistics recording (getting rid of the manual tracking of supervisors and their resources) were considered to be especially important. The supervisors and coordinators emphasized the change in communication, the usefulness of the single platform (fewer emails when 
the communication and materials are in the same place), and the transparency (the supervision is visible).

Of the interviewees, 4 of the 13 interviewees identified only positive experiences, 8 identified both positive and negative, and 1 identified only negative. The experiences were higher in number and more detailed for coordination and supervision, while experiences of administration and management were fewer and more general. The positive experiences were related to the model (an extremely useful, agile model that utilizes in-house competencies well and is generalizable to similar, well-scoped development efforts), the involvement (it has been valuable being able to participate and try out, which also helps in commitment to the result), and influencing the result (the needs of the users have been taken into account).

The negative experiences were doubts about the coverage of the involvement (the piloting phase could have been longer, and more people could have been involved) and coping with incompleteness (some may have felt insecure due to the changes). It is worth noting that the interviewee who stated that he had had only negative experiences still felt that the participation itself was positive and considered related work on the service promise to be helpful. One of the other interviewees also mentioned that the service promise supported his involvement.

In general, the starting orientation of the interviewees was either in business process development (5) or IS development (4), meaning that the role and expectations expressed by the interviewees were related to one of these. Additionally, two interviewees were related to both and two to neither. However, regarding the experiences, this division is no longer visible because the experiences refer to both the process development and the IS development regardless of the starting orientation.

RQ2: How was the user involvement realized in the digitalization project?

The realization of involvement was difficult to pinpoint. While 8 of the 13 interviewees acknowledged having development ideas, most comments were general and included no concrete examples. Instead, they showed trust in taking the ideas into account (there may be something that I have also pointed out, but it is hard to specify a single one). Only a few could name a concrete implemented idea (it was not possible to send a message in a certain situation, but it is now).

However, involvement also meant that interviewees were participants in change management because 10 of the 13 played an active role by communicating process- or tool-related changes (answered questions and provided instructions to the supervisors). The communication was two-directional, as information and guidance were provided to users, and user feedback was relayed to developers (informed developers about the comments from the supervisors and the coordinator team).

\subsection{Research question 3}

As in part one, the second part of the interview also consisted of identifying the role of the interviewees and the responses to 10 open-ended questions and one numeric assessment. In the end, the same two concluding open-ended questions posed to the interviewees in the first part were presented. The open-ended answers were again coded based on the theory presented in Chapter 2 (refer to Section 4.1). 
Of the 27 interviewees, 24 had user experience in the digitalized process - that is, they had used Konto from the perspective of a student (6 interviewees), a thesis supervisor or coordinator (13), or administrative personnel (5).

RQ3: How did the users experience the digitalized process when it was implemented as an IS (Konto thesis monitoring and guidance system)?

The most positive characteristics were the visual clarity and the holistic view of the process (17 answers; everything dealing with the process was on the same view). Eight interviewees mentioned the improved process either as a whole or as a certain detail or phase of the operation (fewer pdfs to be sent; an assessment in the same system). Process automation was mentioned in six answers (credits were saved on the study registry system). Five interviewees also mentioned the following features: streamlined process, process guidance (it forces the users to take certain steps), easier communication (it connects the student and the supervisor), and easy to use.

Of the negative features, the highest number (13) of answers cumulated to the opinion that the system did not have a certain desired function or that it did not function as the user expected. Twelve interviewees felt confusion at some point, which was typically connected to a technical problem (do the credits really transfer to the transcript of records [supervisor]?; In stage 1/3, there were several places where I could hand in the report [student]). However, only two users mentioned that the guidance was inadequate. Eleven interviewees, including one student, detected some sort of resistance to change or to the use of Konto instead of the old system (many students still send emails).

Ten users had some specified features in mind that they would like to see in a digitalized process (the maturity exam should be embedded in Konto; text proofing would be handy; group mail to students is needed). Their wishes were quite dispersed; four dealt with increased automation and a desire for better guidance, and four users also noted a deviation between Konto and the original thesis process.

Nine users felt that the process has been improved and is now more transparent (for a student, there are many things that s/he has to remember in the final phase of the process, [and] Konto reduces confusion; Urkund [plagiarism check] is now used for $100 \%$ certainty; the monitoring of students processes had been more difficult without Konto).

The interaction between students and supervisors has improved, according to six interviewees (interaction is more organized now), but the same number replied that there was no change whatsoever. One student pointed out a negative aspect (a student who is not using the university's email address does not receive Konto notices at the beginning of the process). One supervisor complained about the text editor (is not at the same level as in email).

Offering reasons for better manageability, the users mentioned the visibility of the digitalized process and that everything is in the same place (7 answers). Five users saw that the overall handling of the process was improved via digitalization. There were single opinions that the process was more manageable because of streamlining, forced steps, and record keeping. Two interviewees also mentioned enhanced communication.

The students were asked whether communication with the supervisor was easier within the Konto message system than with standard emails. Of the six students, two 
gave only positive aspects, two saw no difference, and one replied that from the process point of view, having everything in the same place is handy but that some other tools such as Moodle (learning platform) have to be used. Four students estimated that the process handling benefited from Konto, one suspected that it made no difference, and one had little experience because the greater part of the process was still handled outside Konto.

There were 17 positive comments about appearance and usability, and the following adjectives were used: clear, simple, easy, logical, fast, light, tidy, and appropriate. Twelve users also presented negative arguments; five used the word dull when describing the appearance, and old-fashioned and Windows-like were also mentioned in the descriptions. Some pointed out specific features that they did not like or that they found confusing. Eleven users wanted to list improvements that they would like to see in the future. One feature the students would like to add is a peek function to check the contents of the subsequent stages of the process; the supervisors would like to see the actions in more detail during the stages, especially in the final stage, which contains numerous small steps.

The general understanding of the process was at a good enough level to where Konto did not significantly increase it, as indicated in the answers of 19 users. However, the same users were able to point out some details indicating that digitalization was, perhaps, advantageous compared to the old type of process handling. There was only one opinion that Konto had not increased understanding of the process at all, and two users had encountered a confusing situation because of uncertainty regarding whether or not the technique actually worked.

Both the developers and the users were asked to give Konto a grade. The scale was 1 to 10 , with 10 being the best grade. The mean of 22 answers ( 5 were unable to give an assessment) was 8.32, and the standard deviation was 0.78 . The lowest grade was 7 and the highest 10 .

Studying the available documentation and observations showed that there were some difficulties with terminology and with combining old practices related to the process and IS development; some of these only came to light during IS implementation. However, based on the Konto log files, the digitalized process has been undertaken comprehensively.

\subsection{Reliability and validity of the research}

The interviews were planned, tested, and performed by two of the authors of this article. The interviewers consulted each other during the process to avoid irregularities in the interview arrangements. Thus, the data are coherent.

The platform for the questionnaire was the Webropol survey application. During the interviews, the answers were typed straight into Webropol. The interviewees were able to see the typed responses and comment immediately if they detected any misinterpretations in the answers. With this arrangement, we minimized errors in the data. All the interviews were also recorded with the consent of all the interviewees. When crosschecked, the typed data and the contents of the recordings did not deviate from the essential content of the interviews and the expressions of the interviewees.

The interview sessions were performed in face-to-face situations or via Skype meetings (even then, the interviewees were able to monitor the answers as they were 
typed). The sessions were agreed upon beforehand and took place in tranquil environments without interference. The data handling was performed in Excel using standard content analysis - that is, coding and summarizing techniques. During the interviews, the questions appeared to be clear, and the interviewees were able to answer fluently in their own language (Finnish). Both the concept and the construct validity were at the appropriate levels.

The empirical data used in this paper are based on interviews of a relatively small sample of people who are called stakeholders due to their different roles and activities during the project. This is why the interviews were considered to be of an expert nature (Bogner et al. 2009) rather than standard research interviews. Because the full-scale use of Konto has only recently started (the beginning of 2019), the stakeholders' interviews were limited to the staff who were involved in the planning and test-use stages in autumn 2018. The students were randomly selected from Konto and from among those who had either completed or were just completing the thesis process. They do not cover all the HH degree programmes. Therefore, the ecological validity cannot be very firm because the sample consists of the pioneer developers and users, and it may be slightly biased compared to the basic population (all HH staff and students). However, other available data, such as discussions and emails with the more representative, larger number of developers and users are in accordance with the sample data. Moreover, the two interviewers were able to follow data saturation throughout the interview process, and the latest interviews added only minor details.

\section{Discussion and conclusions}

The interview data, Konto logs, documentation, and observations all confirmed that the EXOD model performed well in digitalizing the expert-driven thesis process. The findings met the goals set for the EXOD model: the experts felt that they had been listened to (see e.g. Kotter 1995; see e.g., Davenport 2010); the developed IS, Konto, decreased the workload of the experts (see e.g., Davenport 2010); it was easy to use (e.g. Davis et al. 1989); and it ensured that the process was followed (see e.g. Davenport 2010). The level of process development was meaningful (see e.g., Davenport and Short 1990; Venkatraman 1994) and provided a good basis for the development of the IS. The selected IS development method (see e.g., Lagstedt and Dahlberg 2018b), the hybrid approach (see e.g., Theocharis et al. 2015), was suitable in this case. Moreover, Konto is visually clear, thus enabling effortless comprehension and control over all its features. This supports the understanding of the process and refers to the perceived ease of use (Davis et al. 1989). The given feedback indicates that the thesis process has improved, i.e., the developed IS is also perceived as useful.

The best results were achieved in change management. Thesis supervision is considered to be personal expert work (see e.g., Davenport 2010), and external interventions, such as process enforcing and automation, are often considered undesirable. However, in this case, the experts felt that they could affect the outcome (see e.g., Kotter 1995), and automation - for example, Konto — was seen as useful as it reduced mechanical work and clarified information handling (see e.g., Davis et al. 1989; Davenport and Short 1990; Kotter 1995; Davenport 2010). 
However, there is still room for improvement. Some experts perceive the continuously changing IS as confusing; consequently, plan-driven development could be emphasized. In addition, some felt that the pilot periods were short; therefore, feedback could be collected over a longer period and from a larger user group. Additionally, in some cases, the users claimed to follow the process, but implementing the IS revealed that, in fact, they did not (cf. Argyris 1977). While this cannot be fully avoided, it should be considered in steps 2 and 3 of the EXOD model, and experts should be engaged in pursuing this objective. In addition, some supervisors emphasize their expertise in supervising, while others see it more as routine work; therefore, compromises need to be made.

Interestingly, the EXOD model seems to produce committed change agents (Cameron and Green 2009), even though this was not an explicitly pursued objective. This effect should be studied and further developed to make it more robust. Overall, we recommend that future studies be conducted to refine and test the EXOD model more comprehensively.

The developed IS, Konto, has proven its worthiness at HH. It is now handling over 2000 theses in its database, and the IS itself has been reliable. In addition, even in the IS development emphasis step, the software company (Eduix Ltd) hired to develop the Konto system wanted to buy the rights to Konto and make it their own product (renamed Wihi). In a short period, Eduix has been able to sell the application to three Finnish universities of applied sciences, and ongoing negotiations with several other Finnish universities may lead to new deals in the near future. We view this as one measure of the success of our thesis process digitalization project and the EXOD model.

As universities of applied sciences originally adopted the idea of the thesis from science universities, the process and the purpose of the thesis work is the same. Therefore, all the conclusions in this article will apply to science universities. Also, colleges and other institutes applying a similar concept can benefit from the EXOD model (and Konto/Wihi). The generalization can be extended, not only throughout Europe but also globally, since the university model is rather similar in all countries. Additionally, based on the suitability for processes with high actor expertise and autonomy, we recommend that the EXOD model be used as a baseline for university process digitalization projects in general.

As a next step, we are starting a new, EXOD model-utilizing internship service development project in 2020. In that project, we will collect more experiences with the EXOD model and how it can be improved, and we will further the practical guides for developers.

Availability of data and material Data is available on request (all data in Finnish).

Funding information This research did not receive any specific grant from funding agencies in the public, commercial, or not-for-profit sectors.

\section{Compliance with ethical standards}

Conflicts of interest/competing interests Not applicable.

Code availability Not applicable. 
Open Access This article is licensed under a Creative Commons Attribution 4.0 International License, which permits use, sharing, adaptation, distribution and reproduction in any medium or format, as long as you give appropriate credit to the original author(s) and the source, provide a link to the Creative Commons licence, and indicate if changes were made. The images or other third party material in this article are included in the article's Creative Commons licence, unless indicated otherwise in a credit line to the material. If material is not included in the article's Creative Commons licence and your intended use is not permitted by statutory regulation or exceeds the permitted use, you will need to obtain permission directly from the copyright holder. To view a copy of this licence, visit http://creativecommons.org/licenses/by/4.0/.

\section{References}

Aghaee, N. (2015). Finding potential problems in the thesis process in higher education: Analysis of e-mails to develop a support system. Education and Information Technologies, 20, 21-36. https://doi.org/10.1007 /s10639-013-9262-z.

Alvesson, M., \& Spicer, A. (2012). A stupidity-based theory of organizations. Journal of Management Studies, 49, 1194-1220. https://doi.org/10.1111/j.1467-6486.2012.01072.x.

Argyris, C. (1977). Organizational learning and management information systems. Accounting, Organizations and Society, 2, 113-123.

Bogner A, Littig B, Menz W (2009) Introduction: Expert interviews - An introduction to a new methodological debate. In: Bogner A, Littig B, Menz W (eds) Interviewing Experts. Palgrave Macmillan, pp 1742.

Borg M, Olsson T, Franke U, Assar S (2018) Digitalization of Swedish government agencies - A perspective through the Lens of a software development census. In: International Conference on Software Engineering.

Cameron E, Green M (2009) Making sense of change management, 2nd edn. Kogan Page Ltd.

Chanias, S., Myers, M. D., \& Hess, T. (2019). Digital transformation strategy making in pre-digital organizations: The case of a financial services provider. The Journal of Strategic Information Systems, 28, 17-33. https://doi.org/10.1016/j.jsis.2018.11.003.

Cooper, R. B., \& Zmud, R. W. (1990). Information technology implementation research: A technological diffusion approach. Management Science, 36, 123-139. https://doi.org/10.1287/mnsc.36.2.123.

Coskun, Y. D. (2015). Promoting digital change in higher education: Evaluating the curriculum digitalisation. International Journal of Educational Research, 11, 197-204. https://doi.org/10.19030/jier.v11i3.9371.

Cunningham, W. (1992). Experience report- the WyCash portfolio management system. ACM SIGPLAN OOPS Messenger, 4, 29-30.

Dahlberg T, Lagstedt A (2018) There is still no " fit for all " IS development method : Business development context and IS development characteristics need to match. In: Proceedings of the 51st Hawaii international conference on system sciences.

Dahlberg T, Hokkanen P, Newman M (2016) How business strategy and changes to business strategy impact the role and the tasks of CIOs: An evolutionary model. In: Proceedings of the Annual Hawaii International Conference on System Sciences. pp 4910-4919.

Davenport, T. H. (2010). Process Management for Knowledge Work. In J. vom Brocke \& M. Rosemann (Eds.), Handbook on Business Process Management 1 (2nd ed., pp. 17-35). Heidelberg: Springer Berlin.

Davenport, T. H., \& Short, J. E. (1990). The new industrial engineering : Information technology and business process redesign. Sloan Management Review, 31, 11-27.

Davis, F. D., Bagozzi, R. P., \& Warshaw, P. R. (1989). User acceptance of computer technology: A comparison of two theoretical models. Management Science, 35, 982-1003. https://doi.org/10.1287 /mnsc.35.8.982.

Fitzgerald, M., Kruschwitz, N., Bonnet, D., \& Welch, M. (2014). Embracing digital technology: A new strategic imperative. MIT Sloan Management Review, 55, 1.

Haneem, F., Kama, N., \& Bakar, N. A. A. (2019). Critical influential determinants of IT innovation adoption at organisational level in local government context. IET Software, 13, 233-240.

Hansen P, Hansson H (2015) Optimizing student and supervisor interaction during the SciPro thesis process Concepts and design. In: The 14th international conference on web-based learning ICWL 2015. Pp 245250 .

Hansen S, Lyytinen K (2010) Challenges in contemporary requirements practice. Proceedings of the 34th Annual Hawaii International Conference on System Sciences 1-11. https://doi.org/10.1109 /HICSS.2010.98. 
Hansson H (2014) How to produce quality theses at universities in a large scale: SciPro IT system - supporting the scientific process. In: Proceedings - Frontiers in Education Conference, FIE.

Hastie S, Wojewoda S (2015) Standish group 2015 Chaos report - Q\&a with Jennifer lynch. In: InfoQ, blog. https://www.infoq.com/articles/standish-chaos-2015. Accessed 22 Feb 2018.

Karunaratne, T. (2018). Blended supervision for thesis projects in higher education: A case study. Electronic Journal of e-Learning, 16, 79-90.

Kauppinen R, Lagstedt A, Lindstedt JP (2019) Expert-oriented digitalization of university processes. In: The 4th international symposium on emerging Technologies for Education, SETE 2019.

Kotter JP (1995) Leading change: Why transformation efforts fail. Harvard Business Review 59-67.

Lagstedt A (2015) Diary thesis as a tool for professional growth and for co-operation between universities and business. In: Proceedings of the 2015 UIIN conference in Berlin, Germany (June, 2015).

Lagstedt A, Dahlberg T (2018a) Requirements engineering as a part of business process and information system development. In: Proceedings of the seventh international conference on well-being in the information society: Fighting inequalities (WIS 2018). Pp 35-39.

Lagstedt A, Dahlberg T (2018b) A contingency theory motivated framework to select information system development methods. In: Pacific Asia Conference on Information Systems. pp 1-14.

Larsson K, Hansson H (2011) The challenge for supervision: Mass individualisation of the thesis writing process with less recourses. In: Online Educa Berlin 2011-17th international conference on Technology Supported Learning \& Training. Pp 2007-2009.

Markus, M. L. (2004). Technochange management: Using IT to drive organizational change. Journal of Information Technology, 19, 4-20. https://doi.org/10.1057/palgrave.jit.2000002.

Mathieson K (1991) Predicting User Intentions: Comparing the Technology Acceptance Model with the Theory of Planned Behavior. Information Systems Research (2:3), pp. 173-191 In: Venkatesh V, Morris MG, Davis GB, Davis FD (2003) User acceptance of information technology: Toward a unified view. MIS Q Manag Inf Syst 27:425-478.

Matt, C., Hess, T., \& Benlian, A. (2015). Digital transformation strategies. Business and Information Systems Engineering, 57, 339-343. https://doi.org/10.1007/s12599-015-0401-5.

Moe, N. B., Aurum, A., \& Dybå, T. (2012). Challenges of shared decision-making: A multiple case study of agile software development. Information and Software Technology, 54, 853-865. https://doi.org/10.1016 /j.infsof.2011.11.006.

Pihir I, Tomičić-Pupek K, Furjan MT (2018) Digital transformation insights and trends. In: Proceedings of the Central European Conference on Information and Intelligent Systems. pp 141-150.

Simon, H. A. (1997). Administrative behavior (4th ed.). New York: The Free Press.

Taylor, F. W. (1913). The principles of scientific management. New York: Harper \& Brothers Publishers.

Theocharis G, Kuhrmann M, Münch J, Diebold P (2015) Is water-scrum-fall reality? On the use of agile and traditional development practices. In: International Conference on Product-Focused Software Process Improvement. pp 149-166.

Venkatesh, V., Morris, M. G., Davis, G. B., \& Davis, F. D. (2003). User acceptance of information technology: Toward a unified view. Management Information Systems Quarterly, 27, 425-478. https://oi.org/10.2307/30036540.

Venkatraman, N. (1994). IT-enabled business transformation: From automation to business scope redefinition. Sloan Management Review, 35, 73-87.

vom Brocke, J., \& Sinnl, T. (2011). Culture in business process management : A literature review. Business Process Management Journal, 17, 357-377. https://doi.org/10.1108/14637151111122383.

Wang, Y., Kung, L. A., Wang, W. Y. C., \& Cegielski, C. G. (2018). An integrated big data analytics-enabled transformation model: Application to health care. Information Management, 55, 64-79. https://doi. org/10.1016/j.im.2017.04.001.

Wenger EC, Snyder WM (2000) Communities of practice: The organizational frontier. Harvard Business Review 139-145.

Westerman G, Bonnet D, \& McAfee A (2014) Leading digital: Turning technology into business transformation. Harvard Business Press. In: Pihir I, Tomičić-Pupek K, Furjan MT (2018) Digital Transformation Insights and Trends. Proceedings of the Central European Conference on Information and Intelligent Systems. pp 141-150

Yin RK (2009) Case study research: Design and methods, 4th edn. Sage Publications.

Submission declaration and verification This article is based on the conference proceeding: "ExpertOriented Digitalization of University Processes", published by the same authors in the 4th International Symposium on Emerging Technologies for Education, SETE 2019. However, this article has elaborated 
largely from the earlier proceeding, having much wider perspective and the data used, making this article novel and independent publication.

The work described in the article has not been published previously, it is not under consideration for publication elsewhere, its publication is approved by all authors and tacitly by the responsible authorities where the work was carried out, and, if accepted, it will not be published elsewhere in the same form, in English or in any other language, including electronically without the written consent of the copyright-holder.

Publisher's note Springer Nature remains neutral with regard to jurisdictional claims in published maps and institutional affiliations. 